\title{
Resistance exercise improves physical fatigue in women with fibromyalgia: a randomized controlled trial
}

\author{
Anna Ericsson ${ }^{1,2^{*}}$, Annie Palstam ${ }^{1}$, Anette Larsson ${ }^{1,2}$, Monika Löfgren ${ }^{3}$, Indre Bileviciute-Ljungar ${ }^{3}$, Jan Bjersing ${ }^{4}$,
} Björn Gerdle ${ }^{5}$, Eva Kosek ${ }^{6}$ and Kaisa Mannerkorpi ${ }^{1,2}$

\begin{abstract}
Background: Fibromyalgia (FM) affects approximately 1-3\% of the general population. Fatigue limits the work ability and social life of patients with FM. A few studies of physical exercise have included measures of fatigue in FM, indicating that exercise can decrease fatigue levels. There is limited knowledge about the effects of resistance exercise on multiple dimensions of fatigue in FM. The present study is a sub-study of a multicenter randomized controlled trial in women with FM. The purpose of the present sub-study was to examine the effects of a personcentered progressive resistance exercise program on multiple dimensions of fatigue in women with FM, and to investigate predictors of the potential change in fatigue.
\end{abstract}

Methods: A total of 130 women with FM (age 22-64 years) were included in this assessor-blinded randomized controlled multicenter trial examining the effects of person-centered progressive resistance exercise compared with an active control group. The intervention was performed twice a week for 15 weeks. Outcomes were five dimensions of fatigue measured with the Multidimensional Fatigue Inventory (MFI-20). Information about background was collected and the women also completed several health-related questionnaires. Multiple linear stepwise regression was used to analyze predictors of change in fatigue in the total population.

Results: A higher improvement was found at the post-treatment examination for change in the resistance exercise group, as compared to change in the active control group in the MFI-20 subscale of physical fatigue (resistance group $\Delta-1.7$, SD 4.3 , controls $\Delta 0.0$, SD 2.7, $p=0.013$ ), with an effect size of 0.33 . Sleep efficiency was the strongest predictor of change in the MFI-20 subscale general fatigue (beta $=-0.54, p=0.031, R^{2}=0.05$ ). Participating in resistance exercise (beta $=1.90, p=0.010$ ) and working fewer hours per week (beta $=0.84, p=0.005$ ) were independent significant predictors of change in physical fatigue $\left(R^{2}=0.14\right)$.

Conclusions: Person-centered progressive resistance exercise improved physical fatigue in women with FM when compared to an active control group.

Trial registration: ClinicalTrials.gov NCT01226784. Registered 21 October 2010.

Keywords: Fibromyalgia, Resistance exercise, Exercise, Fatigue, Randomized controlled trial

\footnotetext{
* Correspondence: anna.ericsson@vgregion.se

${ }^{1}$ Institute of Neuroscience and Physiology/Physiotherapy, Sahlgrenska

Academy, University of Gothenburg, Göteborg, Sweden

${ }^{2}$ University of Gothenburg Centre for Person Centered Care (GPCC),

Göteborg, Sweden

Full list of author information is available at the end of the article
} 


\section{Background}

The prevalence of fibromyalgia (FM) is approximately $1-3 \%$ in the general population, increases with age, and is more prevalent in women than in men [1]. In addition to persistent widespread pain and allodynia, patients with FM often experience severe fatigue, sleep disturbances, stiffness, psychological distress and/or cognitive impairment [2-5]. Women with FM have been shown to have impaired physical capacity [6-8] and they are also less physically active compared to healthy controls [9]. FM is a dominating cause of sick leave among female patients with musculoskeletal disorders and has a great impact on quality of life $[6,10]$.

Fatigue is a prominent symptom in patients with FM, which limits their work ability and social life [11-13]. Women with FM have described their fatigue in terms of sleepless nights, physical weakness, social withdrawal, loss of mental energy and overwhelming exhaustion [13]. Socio-demographic aspects such as female gender, younger age, low working capacity and low level of education have been shown to be associated with higher levels of fatigue in FM [14].

Fatigue is commonly assessed with a one-dimensional visual analog scale (VAS), which enables comparisons across studies. However, fatigue is a complex symptom that interacts with several other common FM symptoms. It is thus recommended to be assessed in multiple dimensions, such as physical, mental and general fatigue in patients with FM, especially in non-pharmacological studies $[15,16]$. Fatigue has been shown to be associated with increased distress, muscular tenderness, and poor sleep quality $[14,15,17,18]$. Higher ratings on the subscales of physical fatigue and reduced activity, which are included in the Multidimensional Fatigue Inventory (MFI-20), have been associated with low working capacity, low level of physical activity and impaired physical capacity in women with FM $[15,19,20]$.

Pain catastrophizing influences the perception of pain and other symptoms in many patients with FM, which complicates the treatment and could influence compliance with exercise [21]. Catastrophic thinking has also been suggested to have an influence on fatigue in FM and in other chronic conditions. However previous research on this topic is scarce [22].

The most beneficial treatment for FM requires a multidisciplinary approach combining education, pharmacological treatment, exercise and cognitive behavioral therapy $[23,24]$. Exercise has been found to improve feelings of energy and fatigue in various medical conditions [25]. Different types of exercise are being used for treatment in FM and chronic widespread pain (CWP) in health care, such as aerobic exercise, resistance training, flexibility exercise and body awareness therapy [26].
Few exercise studies have included measures of fatigue in patients with FM. However the findings of these studies indicate that exercise could decrease fatigue levels [26-29]. Aerobic exercise has been shown to improve the MFI-20 dimension of reduced motivation in female patients with FM [30, 31] and global outcome measures of physical capacity and, to some degree, pain and the number of tender points in FM [26].

Resistance exercise has shown positive effects on limitations in activity, pain, global fatigue, depression and muscle strength in patients with FM. However, the quality of evidence of these effects is poor due to the limited number of studies [29]. The present study is a sub-study of a randomized controlled trial (RCT) showing that resistance exercise improved muscle strength, overall health, and current pain intensity in women with FM, when compared to an active control group [32]. The resistance exercise intervention was a person-centered approach, which emphasizes active involvement of the patient in planning the treatment that is suggested to enhance the patient's ability to manage health problems [33]. The principles of person-centeredness were used in the previously published RCT. The details of the exercise program were planned together with each patient to support each participant's ability to manage the exercise and the progression in loads [32].

As high levels of fatigue have been associated with low levels of physical activity and impaired physical capacity in $\mathrm{FM}[15,19,20]$, improvement in physical capacity in patients with FM may result in a reduction in fatigue. To our best knowledge, there is no previous study investigating the effects of resistance exercise on multiple dimensions of fatigue in FM.

The primary aim of the present study was to examine the effects of a person-centered progressive resistance exercise program on multiple dimensions of fatigue in women with FM compared to an active control group, and to investigate predictors of the potential change in fatigue. Second, the effect of resistance exercise on sleep, pain catastrophizing, depression, and anxiety were also explored, as these variables have been shown previously to be associated with fatigue.

\section{Methods \\ Study design}

This is a sub-study of a multicenter randomized controlled trial in women with FM (ClinicalTrials.gov identification number: NCT01226784) [32]. The present sub-study aimed to investigate the effects of resistance exercise on multidimensional fatigue in women with FM.

\section{Recruitment}

Inclusion and exclusion criteria have been described in detail previously [32]. In short, the inclusion criteria 
were women aged 20-65 years, meeting the American College of Rheumatology (ACR) 1990 classification criteria for FM [2], and the exclusion criteria were other severe somatic or psychiatric disorders, participation in a rehabilitation program within the past year, or inability to understand Swedish.

Female patients with FM were recruited by newspaper advertisement in the local newspapers of three cities in Sweden (Gothenburg, Stockholm, and Linköping) to the multicenter experimental study [32]. There were 130 patients with FM included in the study, and they were randomized to the resistance exercise group $(n=67)$ or the active control group $(n=63)$. The process of recruitment and randomization has been described in detail in a previous publication [32]. No significant differences were found in sociodemographic data between the resistance exercise group $(n=67)$ and the active control group ( $n=63)$ (Fig. 1) [32].

All participants were invited to a post-treatment examination after 15 weeks and $84 \%(n=56)$ in the resistance exercise group and $76 \%(n=49)$ in the active control group completed the test. Seventeen participants (25\%) in the resistance exercise group and $20(32 \%)$ in the active control group discontinued the intervention due to various reasons [32]. Five participants in the resistance exercise group reported adverse effects and chose to discontinue the intervention due to increased pain. Two of these participants completed post-treatment examinations (Fig. 1). Modified figure from [32].

\section{Interventions}

\section{Resistance exercise}

The person-centered progressive resistance exercise intervention was performed twice a week for 15 weeks at physiotherapy premises and at a local gym and was supervised by experienced physiotherapists. The exercise program was standardized and performed in groups of five to seven participants but the load was adjusted individually. The exercise session started with 10 minutes of warm up followed by 50 minutes of resistance exercises focused on large muscle groups in all four extremities and trunk. The resistance exercise was initiated at $40 \%$ of 1 repetition maximum (RM) and progressed up to $80 \%$ of 1 RM during the 15 weeks. Possibilities for progression of loads were evaluated every $3-4$ weeks. Forty-two participants $(62.7 \%)$ in the resistance exercise group reached exercise loads of $80 \%$ of 1 RM while seven participants (10.4\%) reached exercise loads of $60 \%$ of $1 \mathrm{RM}$. The median attendance rate at the resistance exercise sessions was $71 \%$ (range $0-100 \%)$. The procedure of the resistance exercise and adjustment of loads in the present study has been described in detail previously [32].

\section{Active control group}

The active control treatment consisted of relaxation therapy, which was performed twice a week for 15 weeks, guided by experienced physiotherapists and conducted at physiotherapy premises in groups of five to eight participants. It was performed as autogenic training [34], which refers to a series of mental exercises including autosuggestion and relaxation. The relaxation therapy lasted for approximately 25 minutes, followed by stretching exercises. The median attendance rate at the relaxation therapy sessions was $64 \%$ (range $0-100 \%$ ). The procedure in the active control group has been described in detail previously [32].

\section{Measurements}

The patients were referred to a baseline examination which included a tender-point examination [2] by a physician, performance-based tests of physical capacity conducted by physical therapists, and a battery of selfreported questionnaires [32].

\section{Background data}

Background data such as age, education, employment, duration of pain, sick leave, disability pension, and medication were obtained by a standardized interview. Duration of widespread pain was reported in years and obtained by a standardized interview. Employment was divided into four categories of percentage of full-time work: 0 \%; 1-49 \%; 50-79 \%; and 80-100 \%. Full-time work was defined as $40 \mathrm{~h}$ per week.

\section{Self-reported questionnaires Multidimensional Fatigue Inventory (4-20)}

The MFI-20 comprises 20 statements on a 5-point Likert scale that addresses aspects of fatigue experienced during the most recent days. The scores generate five subscales of fatigue: general fatigue, physical fatigue, mental fatigue, reduced motivation, and reduced activity. The scores range from 4 to 20 for each subscale and higher scores refer to a higher degree of fatigue [35, 36]. The MFI-20 has been shown to have satisfactory convergent construct validity and test-retest reliability in FM [37].

\section{FIQ fatigue (0-100)}

The VAS for fatigue included in the Fibromyalgia Impact Questionnaire (FIQ) [38] was used as a one-dimensional measure of fatigue in this study, ranging from $0 \mathrm{~mm}$ (no tiredness) to $100 \mathrm{~mm}$ (very tired). The FIQ for fatigue has been validated and shown satisfactory test-retest reliability in Swedish patients with FM [39].

\section{FIQ pain (0-100)}

The VAS for pain is a subscale of the FIQ that measures current pain intensity. The participant was 


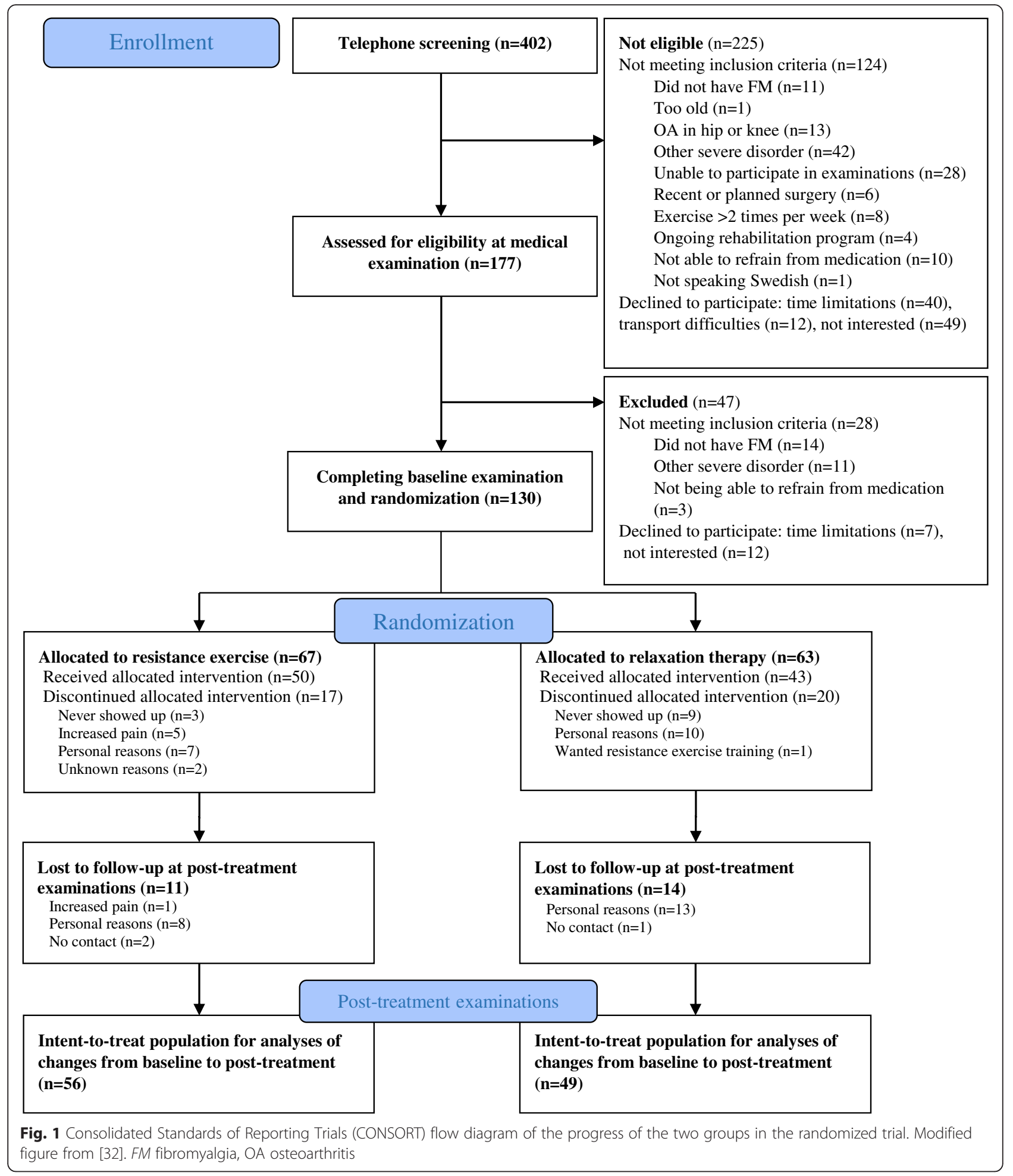

asked to rate her current pain intensity, ranging from $0 \mathrm{~mm}$ (no pain at all) to $100 \mathrm{~mm}$ (worst imaginable pain) [38]. The FIQ for pain was used only in the analyses of predictors of potential change in fatigue.
Pittsburgh Sleep Quality Index (PSQI) (0-21)

The PSQI assesses sleep quality and disturbances over a 1-month period. It comprises nineteen items (scored 0-3), which constitute seven subscales: sleep quality, sleep latency, sleep duration, sleep efficiency, sleep 
disturbances, need of medications to sleep (use of sleeping medication) and daytime dysfunction. The sum of scores for the seven subscales generate one total score (0-21). A PSQI total score $>5$ indicates poor sleep [40]. The PSQI has been used previously in studies of FM $[41,42]$.

\section{Pain catastrophizing scale (PCS) (0-52)}

The PCS assesses pain-related catastrophic thinking. The patients estimate on a 5-point Likert scale ( 0 (not at all) to 4 (all the time)) the extent to which they experience 13 thoughts or feelings while they feel pain. The PCS total score (0-52) is the sum of the scores of the 13 items [43]. A PCS total score $>24$ displays a high level of catastrophic thinking in patients with sub-acute whiplash-related pain [44]. The 13 items also generate three subscales; rumination, helplessness and magnification [43]. The three PCS subscales and the total score were used in the present study in between-group analyses of change over time, while only the PCS total score was used in the analyses of predictors of change in fatigue. The PCS has been tested for validity and reliability $[45,46]$ and has been used in studies of FM [47-49]

\section{Hospital Anxiety and Depression Scale (HADS) (0-21)}

The HADS contains 14 statements, ranging from $0-3$, and a higher score refers to a higher degree of distress. The scores of the 14 items build two subscales: HADSA for anxiety (0-21) and HADS-D for depression (0-21) [50]. A cutoff score of 8 is suggested to indicate possible anxiety or depression [51].

\section{Tests of physical capacity}

\section{Leisure Time Physical Activity Instrument (LTPAl) (h)}

The patients estimate their amount of physical activity in leisure time during a typical week [52]. The physical activities were divided into three categories: light, moderate, and heavy activities, and examples of such activities were given for each category. The LTPAI total score is the sum of hours in all three categories and was used in the present study only in the analyses of potential predictors of change in fatigue.

\section{The 6-minute walk test (6MWT) (m)}

The patient was instructed to walk for 6 minutes as quickly as she could without running and the total walking distance was measured [53]. The 6MWT was used in the present study only in the analyses of potential predictors of change in fatigue.

\section{Statistics}

Data were computerized and analyzed using the Statistical Package Software for the Social Sciences (SPSS version 22, Chicago, IL, USA). Descriptive statistics are presented as mean, standard deviation (SD) and range for continuous variables and as number $(n)$ and percent (\%) for categorical variables.

For comparison between two groups, normal distribution of data collected with questionnaires could not be assumed and the non-parametric Mann-Whitney $U$ test was used for continuous variables, Mantel Haenszel chisquared test for ordered categorical variables and Fisher's exact test for dichotomous variables. Change over time from baseline to 15 weeks within groups was analyzed using the Wilcoxon signed rank test. Effect size was calculated with Cohen's $d$ for outcomes showing a significant change, by dividing the mean difference between the post-treatment score and baseline score in the resistance exercise group and in the active control group by the pooled SD for difference. Effect sizes from 0.20 to $<0.50$ were regarded as small and effect sizes from 0.50 to $<0.80$ were regarded as moderate [54].

A baseline difference was found between the groups in the PSQI subscale of sleep efficiency. The betweengroup analyses were therefore adjusted for PSQI sleep efficiency in linear regression analyses with outcome variables (mean difference post treatment compared to baseline) included as dependent variables and the group variable (intervention/active control) and PSQI sleep efficiency included as independent variables. The assumptions of normality in regression analyses were confirmed by checking the residual scatter plots and histograms of each variable, respectively. To control for possible type 1 errors, the upper limit of the expected number of false significant results for analyses of primary outcomes (the five subscales of the MFI-20) was calculated by the following formula:

$$
\begin{aligned}
& \alpha / 1-\alpha \\
& \quad \times(\text { Number of tests }- \text { Number of significant tests }),
\end{aligned}
$$

where $\alpha$ is the significance level.

Correlation was assessed between the difference between post-treatment and baseline in the five subscales of the MFI-20 and the baseline values for the variables age, employment, duration of widespread pain, FIQ pain, the PCS, the HADS, the PSQI, the LTPAI and the 6MWT, using Spearman's correlation coefficient $\left(r_{\mathrm{s}}\right)$. These variables were chosen based on results from previous studies of correlation between fatigue and other patient characteristics $[15,22]$. In order to find independent baseline predictors of change in fatigue for each MFI-20 subscale, the variables with a Spearman's correlation $p$ value $p<0.1$ with the MFI-20 subscale and group of randomization were entered into a multiple linear stepwise regression analysis with change in the fatigue subscale as the dependent variable. Multiple linear stepwise regression analyses were performed of the subscales 
of the MFI-20 that were found to be significantly correlated with more than one variable. All tests were twosided and conducted at the $5 \%$ significance level.

\section{Results}

\section{Between-group comparisons}

Results of between-group comparisons are shown in Table 1.

\section{Multidimensional fatigue}

There was significantly greater improvement at the posttreatment examination according to change in the MFI20 subscales for general fatigue $(p=0.031)$, physical fatigue $(p=0.013)$ and mental fatigue $(p=0.008)$ in the resistance exercise group, as compared to the change over time in the active control group (Table 1). The mean improvements in the resistance exercise group from baseline to post treatment were $7.5 \%$ in general fatigue, $10.6 \%$ in MFI-20 physical fatigue and $10.7 \%$ in mental fatigue. There were no statistically significant differences between the two groups in change in the MFI20 subscales for reduced motivation or reduced activity at the post-treatment examination (Table 1).

There was a baseline difference between the resistance exercise group and the active control group in the PSQI subscale of sleep efficiency (mean 1.9, SD 1.1 versus mean 1.4, SD 1.2, $p=0.027$ ) (Table 1). When the between-group analyses of the MFI-20 were adjusted for PSQI sleep efficiency, the difference between groups in change of fatigue was significant only for the MFI-20 subscale physical fatigue $(p=0.044)$ (Table 1$)$. The effect size of change in MFI-20 for physical fatigue in the resistance exercise group compared to the active control group was 0.33 (i.e., a small effect size).

Type 1 error: the between-group analyses of primary outcomes (the five subscales of the MFI-20) comprised a total of five statistical analyses, with one significant value at the significance level 0.05 , and the upper level of the number of false significance results was 0.21 , which indicates that $0-1$ of the significant results observed might be false.

\section{Exploratory outcomes}

No statistically significant differences were found between the resistance exercise group and the relaxation group in change in the FIQ for fatigue, the PSQI, the PCS or the HADS at the post-treatment examination (Table 1).

\section{Within-group analyses of exploratory outcomes, and change from baseline to post treatment}

Results of within-group analyses of outcomes, and change from baseline to post treatment are shown in Table 1.

\section{The FIQ for fatigue}

The resistance exercise group improved in the FIQ for fatigue over time from baseline to post treatment (mean difference -8.6, SD 21.2, $p=0.002$ ) (Table 1).

\section{The PSQI}

The resistance exercise group improved over time in the PSQI subscale for sleep quality (mean difference -0.2 , SD 0.8, $p=0.047$ ), while the active control group improved in the PSQI subscale for need of medications to sleep (mean difference 0.3 SD 1.0, $p=0.036$ ) (Table 1).

\section{The PCS}

The resistance exercise group improved significantly over time in all three PCS subscales and the PCS total score (mean difference in PCS total score -2.7 SD 7.6, $p=0.004)$. In the active control group there was a tendency towards improvement in two PCS subscales and the PCS total score $(p=0.051-0.056)$ (Table 1$)$.

\section{The HADS}

No significant changes during the study period were found within any of the groups for HADS anxiety or HADS depression (Table 1).

\section{Predictors of change in fatigue}

The baseline values of the variables included in the correlation analysis are presented in Table 1 and in a previous publication [32]. The results of the correlation analysis are presented in Table 2. Multiple linear stepwise regression analyses were carried out on the subscales of the MFI-20 that were found to be significantly correlated with more than one variable, which were general fatigue and physical fatigue. Variables correlated with change in MFI-20 subscales with a $p$ value $<0.1$ were included together with intervention group (resistance/control) in the multiple linear stepwise regression analyses of predictors of change in the MFI-20 subscales.

\section{MFI-20 general fatigue}

Intervention (resistance/control), employment, the PSQI for sleep efficiency and the FIQ for pain were associated $(p<0.1)$ with change in the MFI-20 for general fatigue (Tables 1 and 2) and were included in the multiple linear stepwise regression analysis for general fatigue. After the PSQI for sleep efficiency was entered into the stepwise model as the first variable, no additional variable was entered $(B=-0.54$, SE $0.25, p=0.031)$. The $R^{2}$ value for the model was 0.05 . Poorer sleep efficiency at baseline predicted improvement in general fatigue. 
Table 1 Baseline values, change from baseline in outcome variables, and within-group and between-group differences in change in the resistance exercise group and the active control group

\begin{tabular}{|c|c|c|c|c|c|}
\hline \multicolumn{3}{|c|}{ Resistance exercise group } & \multicolumn{3}{|c|}{ Active control group } \\
\hline $\begin{array}{l}\text { Baseline } n=67 \\
\text { Mean (SD) }\end{array}$ & $\begin{array}{l}\triangle 15 \text { weeks } n=56 \\
\text { Mean }(S D), \min , \max \end{array}$ & $\begin{array}{l}\text { Within-group } \\
\text { analysis } p \text { value }\end{array}$ & $\begin{array}{l}\text { Baseline } n=63 \\
\text { Mean (SD) }\end{array}$ & $\begin{array}{l}\Delta 15 \text { weeks } n=49 \\
\text { Mean }(S D), \text { min, max }\end{array}$ & $\begin{array}{l}\text { Within-group } \\
\text { analysis } p \text { value }\end{array}$ \\
\hline
\end{tabular}
Resistance vs active control group

Between-group Between group Between-group analysis of baseline analysis of change analysis of change $p$ value adjusted $p$ value

MFI-20

gue

$17.3(2.7) \quad-1.3(3.1)-10,-7-0.003$

$\begin{array}{ll}-1.3(3.1),-10,-7 & 0.003\end{array}$

$17.8(2.74) \quad-0.5(2.6),-9,-4 \quad 0.48$

0.37

Mental fatigue

\section{$15.0(3.3)$}

$-1.6(3.4),-10,-7 \quad 0.001$

$16.5(2.9)$

$0.0(2.7),-8,-5$

0.17

0.031

0.013

$\mathbf{0 . 0 4 4}$

Reduced activity

$14.6(3.4)$

$-1.0(3.6),-13,-6 \quad 0.055$

$15.0(4.0)$

$-0.1(2.5),-6,-5 \quad 0.85$

$15.2(3.5)$

$-0.1(2.8),-8,-5 \quad 0.89$

Reduced motivation

Exploratory outcomes

FIQ fatig

Duration of sleep

Duration of sleep $1.1(1.1) \quad-0.0(0.9),-3,-3 \quad 0.73$

Sleep efficiency $1.9(1.1)$

Sleep disturbance $2.0(0.6)$

$-0.3(1.0),-3,-1-0.061$

$0.0(0.6),-1,-1 \quad 1.00$

Sleep latency

$1.7(1.0)$

Day dysfunction

$1.6(0.8)$

$-0.1(0.8),-2,-1$

$-0.1(0.8),-2,-2$

0.26

Sleep quality

$1.8(0.8)$

$-0.2(0.8),-2,-1$

0.45

Need meds to sleep

$1.0(1.3)$

$-0.1(1.2),-3,-3$

$\mathbf{0 . 0 4 7}$

PSQI total score

$10.9(4.3)$

$-0.6(3.4),-11,-9$

0.69

$10.4(3.6)$

$0.4(2.8),-8,-6 \quad 0.34$

0.56

0.008

0.070

PCS

\begin{tabular}{|c|c|c|c|c|c|c|c|c|c|}
\hline Rumination & $6.3(3.6)$ & $-0.9(3.5),-8,-12$ & 0.046 & $6.6(4.3)$ & $-0.8(3.2),-8,-10$ & 0.056 & 0.81 & 0.97 & 0.11 \\
\hline Magnification & $3.4(2.5)$ & $-0.6(1.9),-4,-4$ & 0.030 & $3.6(2.8)$ & $-0.4(2.0),-5,-3$ & 0.25 & 0.82 & 0.50 & 0.18 \\
\hline Helplessness & $9.7(5.3)$ & $-1.3(4.0),-10,-9$ & 0.012 & $10.1(5.9)$ & $-1.6(4.6),-15,-6$ & 0.051 & 0.84 & 0.84 & 0.49 \\
\hline PCS total score & $19.4(10.0)$ & $-2.7(7.6),-17,-19$ & 0.004 & $20.3(11.9)$ & $-2.8(7.9),-25,-11$ & 0.055 & 0.88 & 0.58 & 0.16 \\
\hline \multicolumn{10}{|l|}{ HADS } \\
\hline Depression & $7.0(3.9)$ & $-0.7(3.7),-9,-11$ & 0.086 & $6.7(3.5)$ & $0.3(2.8),-6,-12$ & 0.49 & 0.80 & 0.082 & 0.11 \\
\hline Anxiety & $7.9(4.7)$ & $-0.3(3.6),-11,-8$ & 0.58 & $8.0(4.5)$ & $0.5(2.7),-9,-8$ & 0.10 & 0.94 & 0.22 & 0.099 \\
\hline
\end{tabular}

MFI-20 Multidimensional Fatigue Inventory, FIQ Fibromyalgia Impact Questionnaire, PSQI Pittsburgh Sleep Quality Index, PCS Pain Catastrophizing Scale, HADS Hospital Anxiety and Depression Scale * $p$ value adjusted for PSQI sleep efficiency

$81.8(15.8) \quad-5.5(19.0),-81,-73 \quad 0.11$

0.95

0.12

0.069

0.78

0.061

0.32

$1.1(1.2) \quad-0.2(0.9),-2,-2 \quad 0.22$

$0.1(1.2),-2,-3 \quad 0.55$

$2.0(0.6)$

$0.1(0.6),-1,-1 \quad 0.35$

$\begin{array}{lll}1.8(1.0) & 0.0(0.8),-2,-2 & 0.84\end{array}$

$\begin{array}{lll}1.7(0.8) & 0.0(0.8),-2,-2 & 1.00\end{array}$

$1.9(0.8)$

$0.0(0.8),-1,-2$

$1.0(1.3)$

$0.3(1.0),-2,-3$

0.69

0.036

0.94

0.27

0.18

$\mathbf{0 . 0 2 7}$

0.46

0.26

0.89

0.37

0.83

0.14

0.50

0.37

0.49

0.90

0.82

0.32

0.65

0.16

$10.8(4.0)$

$0.5(3.0),-5,-9$

0.48

0.19

0.10

$p$ values $<0.05$ are marked in bold print 
Table 2 Spearman's correlation coefficients $\left(r_{s}\right)$ with $p$ values for correlation between change (posttest-baseline) in the five subscales of the Multidimensional Fatigue Inventory-20 and patient characteristics, symptoms and physical function $(n=105)$

\begin{tabular}{|c|c|c|c|c|c|}
\hline & $\begin{array}{l}\text { Change in general } \\
\text { fatigue } r_{s}, p \text { value }\end{array}$ & $\begin{array}{l}\text { Change in physical } \\
\text { fatigue } r_{s}, p \text { value }\end{array}$ & $\begin{array}{l}\text { Change in mental } \\
\text { fatigue } r_{s}, p \text { value }\end{array}$ & $\begin{array}{l}\text { Change in reduced } \\
\text { activity } r_{s}, p \text { value }\end{array}$ & $\begin{array}{l}\text { Change in reduced } \\
\text { motivation } r_{s,} p \text { value }\end{array}$ \\
\hline$\overline{\text { Age }}$ & $-0.09,0.36$ & $0.00,0.98$ & $0.01,0.89$ & $0.027,0.78$ & $0.033,0.74$ \\
\hline Employment & $0.23,0.021$ & $0.26,0.008$ & $0.09,0.35$ & $0.11,0.28$ & $0.05,0.62$ \\
\hline Duration CWP & $0.00,0.98$ & $-0.07,0.47$ & $0.04,0.70$ & $0.10,0.33$ & $0.10,0.33$ \\
\hline FIQ pain & $-0.17,0.079$ & $-0.14,0.15$ & $0.15,0.12$ & $-0.12,0.23$ & $0.02,0.85$ \\
\hline PCS total & $0.02,0.84$ & $0.03,0.80$ & $0.02,0.86$ & $-0.04,0.69$ & $0.09,0.39$ \\
\hline HADS-D & $0.00,0.98$ & $-0.02,0.83$ & $-0.12,0.21$ & $0.04,0.70$ & $-0.030,0.76$ \\
\hline HADS-A & $0.06,0.52$ & $0.11,0.26$ & $-0.11,0.28$ & $0.14,0.16$ & $0.12,0.24$ \\
\hline \multicolumn{6}{|l|}{ PSQI } \\
\hline Duration of sleep & $-0.02,0.84$ & $-0.06,0.55$ & $-0.09,0.39$ & $-0.06,0.58$ & $-0.10,0.36$ \\
\hline Sleep efficiency & $-0.21,0.049$ & $-0.21,0.044$ & $-0.21,0.048$ & $-0.06,0.54$ & $-0.22,0.037$ \\
\hline Sleep disturbance & $-0.03,0.74$ & $0.09,0.39$ & $0.04,0.67$ & $0.16,0.12$ & $0.04,0.69$ \\
\hline Sleep latency & $-0.15,0.15$ & $-0.05,0.62$ & $-0.05,0.66$ & $-0.08,0.46$ & $-0.07,0.54$ \\
\hline Day dysfunction & $0.06,0.52$ & $0.03,0.74$ & $0.00,0.95$ & $-0.08,0.40$ & $0.14,0.18$ \\
\hline Sleep quality & $-0.03,0.75$ & $-0.02,0.84$ & $-0.05,0.63$ & $0.05,0.63$ & $0.14,0.17$ \\
\hline Need meds to sleep & $-0.14,0.15$ & $-0.08,0.41$ & $-0.11,0.28$ & $0.00,0.99$ & $0.03,0.80$ \\
\hline Total score & $-0.10,0.31$ & $-0.11,0.30$ & $-0.13,0.20$ & $-0.06,0.53$ & $-0.4,0.67$ \\
\hline LTPAI & $-0.09,0.38$ & $0.08,0.44$ & $-0.02,0.83$ & $0.11,0.29$ & $-0.04,0.69$ \\
\hline 6-minute walk test & $0.06,0.53$ & $0.10,0.33$ & $-0.09,0.35$ & $-0.04,0.71$ & $-0.13,0.19$ \\
\hline
\end{tabular}

Correlation coefficients with a $p$ value $<0.1$ are marked in bold print. CWP chronic widespread pain, FIQ Fibromyalgia Impact Questionnaire, PCS Pain Catastrophizing Scale, HADS-D Hospital Anxiety and Depression Scale - subscale of depression, HADS-A Hospital Anxiety and Depression Scale - subscale of anxiety, PSQI Pittsburgh Sleep Quality Index, meds medications, LTPAI Leisure Time Physical Activity Instrument

\section{MFI-20 physical fatigue}

Intervention (resistance/control), employment and the PSQI for sleep efficiency were associated $(p<0.1)$ with change in the MFI-20 for physical fatigue (Tables 1,2) and were included in multiple linear stepwise regression analysis of physical fatigue. Intervention $(B=1.90, \mathrm{SE}=$ $0.73, p=0.010)$ and employment status $(B=0.8, \mathrm{SE}=$ $0.29, p=0.005)$ were independent predictors of change in physical fatigue; $R^{2}$ for the model was 0.14 . Participating in the resistance exercise intervention and working fewer hours per week at baseline predicted improvement in physical fatigue.

\section{Discussion}

The present randomized controlled trial investigated the effects of a 15-week person-centered progressive resistance exercise program on multiple dimensions of fatigue in 130 women with FM. Significant improvements were found for change in the MFI-20 subscales for general fatigue, physical fatigue, and mental fatigue in the resistance exercise group in comparison with the active control group. When the analyses were adjusted for baseline differences in sleep efficiency the betweengroup difference was significant for MFI-20 physical fatigue only. The effect size for MFI-20 physical fatigue was small (0.33) but lies within the expected range according to a recent meta-analysis, which investigated the effects of exercise on fatigue in patients with FM [55]. The MFI-20 physical subscale reflects fatigue related to "physical ability to do things" and "physical condition", physical components that are expected to improve with exercise. Although the improvement in physical fatigue was small in effect size, it is valuable for patients describing themselves as physically weak and becoming fatigued after doing very little [56], which causes deterioration in their quality of life and ability to manage daily activities. The MFI-20 subscale for physical fatigue has been used separately by the Outcome Measures in Rheumatology (OMERACT) group in analyses aiming to identify subgroups in FM [57].

A previous study found that decreased fatigue in patients with FM engaging in exercise was associated with changes in adipokines and insulin-like growth factor-1, which appear to be biological correlates of exercise and fatigue [58]. We were also interested in investigating which variables could predict the possible change in fatigue. Participating in resistance exercise combined with working fewer hours per week at baseline predicted greater improvement in the MFI-20 subscale for physical fatigue. The PSQI for sleep efficiency predicted improvement in the MFI-20 for general fatigue, which indicates that the women with FM who had worse sleep efficiency 
at baseline were more likely to improve their general fatigue regardless of whether they participated in resistance exercise or in the active control group. Sleep efficiency in the PSQI refers to the time asleep per night in relation to the time spent in bed. These findings indicate that women with FM who have the worst sleep efficiency might have the most to gain from any intervention. However, the explained variance ranged from $5-4 \%$ in the analyses of the MFI-20 subscales, and the improvement in fatigue was reasonably influenced by other factors not investigated in the present study.

Variables that have been previously found to be associated with dimensions of fatigue were included in the correlation analyses; however, only a few variables appeared to be associated with change over time in fatigue. The participants' age or duration of pain did not appear to have an influence on change in fatigue, nor did their level of psychological distress or physical capacity. These results indicate that women with FM could gain improvements in fatigue by resistance exercise regardless of individual factors. Similar results have also been found for improvements in pain disability [59].

Fatigue is a symptom with a great negative effect on daily life in women with FM $[11,13,60]$ and has been recommended to be assessed in multiple dimensions $[15,61]$, yet the effects of resistance exercise on multidimensional fatigue in FM have not been previously studied. However, a few studies have investigated the effect of resistance exercise on global fatigue assessed with a VAS $[62,63]$. In the present study the FIQ for global fatigue was included for exploratory analysis. There was significant improvement in the FIQ for global fatigue within the resistance exercise group but there were no significant differences in change in the FIQ for global fatigue between the resistance exercise group and the control group. These results are in line with previous studies by Jones et al. [62] comparing resistance exercise with flexibility exercise, and by Häkkinen et al. [63] comparing resistance exercise with a control group in FM; both studies showed a significant change within the resistance exercise group in a VAS for global fatigue, but there were no significant differences in the change in global fatigue in comparison with controls. These findings endorse the use of a multidimensional assessment of fatigue in terms of physical fatigue, which was sensitive to change induced by resistance exercise.

Exploratory analyses were carried out in the present study aiming at investigating the effects of resistance exercise on the PSQI, the PCS and the HADS as compared to the active control group. In the analyses of change over time in the PSQI, the resistance exercise group had significant within-group improvements in the subscale for sleep quality and the active control group reported significant improvement in the subscale for needing medications to sleep, after the 15-week intervention. However, there were no significant between-group differences in change for any of the PSQI subscales. This is line with the results of a previous study of resistance exercise in women with FM [63].

There were significant within-group improvements over time in pain catastrophizing in the PCS total score and all three subscales in the resistance exercise group. However, there were no significant between-group differences in change, possibly because the control group also tended towards improvement in the PCS.

No significant changes were found for change in depression or anxiety assessed with the HADS in the resistance exercise group or the active control group. Also in previous exercise studies, the effect on depression and anxiety in FM has been found to be limited [31, 64].

Recent publications have recommended resistance exercise for patients with FM $[65,66]$. The resistance exercise program in the present study had a person-centered approach and was progressively increased over 15 weeks. Over $60 \%$ of the participants managed to increase the loads up to $80 \%$ of $1 \mathrm{RM}$ and the attendance was satisfactory at $71 \%$. Only $5(7 \%)$ of the participants in the resistance exercise group discontinued the intervention due to increased pain, which indicates that a majority of women with FM tolerate individually tailored resistance exercise twice a week for over 3 months. The resistance exercise program had a person-centered approach, which most likely contributed to the high attendance rate and low occurrence of adverse effects, as the approach enhances self-efficacy and sense of control in the participants. The resistance exercise program in the present study had similarities with the programs in the studies by Jones et al. [62] and Häkkinen et al. [63], which also were progressed and performed twice a week [62]. Relaxation therapy was chosen as the active control treatment in the present study and was assumed to improve overall wellbeing in the women with FM.

\section{Limitations}

The present study is a sub-study and the statistical power was calculated with regards to the primary analysis published previously [32]. The number of included participants was also considered to be sufficient for the aim of the present study, and there was a significant difference between the groups in change in physical fatigue. The results of the present study must be interpreted with caution because the upper limit of the expected number of false significant results was calculated to be 0.21 for the primary outcomes, which indicates that $0-1$ of the significant results could be false. A large number of tests of correlation were also performed in the analyses of predictors, and the values of explained variance 
$\left(R^{2}\right)$ in the multiple linear regression analyses were low, ranging from 0.05 to 0.14 , which could be in the margin of error for the subscales.

Positive expectations of exercise have been found to play a role in the effect of exercise on psychological outcomes [67]. The participants in the present study were recruited by newspaper advertisement, which could have attracted persons with FM with expectations of improvement and a positive attitude towards resistance exercise. This might have influenced the magnitude of improvement and compliance with the exercise protocol. However, the same recruitment method was used for both groups and they were recruited simultaneously, thus the recruitment method would not have affected the outcome in group comparisons.

\section{Conclusions}

The present study is the first to show that personcentered progressive resistance exercise contributed to improvement in physical fatigue in women with FM. Aspects of work and sleep were found to contribute to the improvement in fatigue.

\begin{abstract}
Abbreviations
ACR, American College of Rheumatology; CWP, chronic widespread pain; FIQ Fibromyalgia Impact Questionnaire; FM, fibromyalgia; HADS, Hospital Anxiety and Depression Scale; LTPAI, Leisure Time Physical Activity Instrument; MFI-20, Multidimensional Fatigue Inventory; PCS, Pain Catastrophizing Scale; PSQI, Pittsburgh Sleep Quality Index; RCT, randomized controlled trial; RM, repetition maximum; VAS, visual analog scale
\end{abstract}

\section{Acknowledgements}

We would like to thank all colleagues who performed examinations and supervised the groups in Gothenburg, Alingsås, Linköping, and Stockholm. The study was supported by the Swedish Rheumatism Association, the Swedish Research Council, the Health and Medical Care Executive Board of Västra Götaland Region, ALF-LUA at Sahlgrenska University Hospital, Stockholm and Östergötland County Councils (ALF), and AFA Insurance and Gothenburg Center for Person Centered Care (GPCC). The authors declare no conflicts of interest.

\section{Availability of data and materials}

Data will not be shared, as more analyses are planned for the material.

\section{Authors' contributions}

The authors of this multicenter study have contributed as follows and their research site is also specified: AE (Gothenburg) worked with data analysis, interpretation of data and manuscript writing; AP and AL (Gothenburg) worked with study design and acquisition; ML (Stockholm) worked with acquisition; IB-L (Stockholm) participated in study design and acquisition; JB (Gothenburg) worked with acquisition and interpretation of data; BG (Linköping) worked with study conception, study design, and acquisition; EK (Stockholm) worked with study conception, study design, and acquisition; KM (Gothenburg) worked with study conception, study design, acquisition, data analysis, interpretation of data, and manuscript writing. All the authors were involved in the drafting of the article and revising it critically for important intellectual content. All the authors approved the final version of the article.

\section{Competing interests}

The authors declare that they have no competing interests.

\section{Ethics approval and consent to participate}

The study was approved by the Regional Ethics Committee in Stockholm (2010/1121-31/3). Written and oral information was given to all participants and written consent was obtained from all participants.

\section{Author details}

${ }^{1}$ Institute of Neuroscience and Physiology/Physiotherapy, Sahlgrenska Academy, University of Gothenburg, Göteborg, Sweden. ${ }^{2}$ University of Gothenburg Centre for Person Centered Care (GPCC), Göteborg, Sweden. ${ }^{3}$ Karolinska Institutet, Department of Clinical Sciences, Danderyd Hospital Stockholm, Stockholm, Sweden. ${ }^{4}$ Institute of Medicine, Department of Rheumatology and Inflammation research, Sahlgrenska Academy, University of Gothenburg, Göteborg, Sweden. ${ }^{5}$ Department of Medical and Health Sciences, Division of Community Medicine, Faculty of Medicine and Health Sciences, Linköping University, Pain and Rehabilitation Center, Anesthetics, Operations and Specialty Surgery Center, Region Östergötland, Linköping, Sweden. ${ }^{6}$ Department of Clinical Neuroscience, Karolinska Institutet, Stockholm, Sweden.

Received: 15 March 2016 Accepted: 6 July 2016

Published online: 30 July 2016

\section{References}

1. Gran JT. The epidemiology of chronic generalized musculoskeletal pain. Best Pract Res Clin Rheumatol. 2003;17(4):547-61.

2. Wolfe F, Smythe HA, Yunus MB, Bennett RM, Bombardier C, Goldenberg DL, Tugwell P, Campbell SM, Abeles M, Clark P et al. The American College of Rheumatology 1990 criteria for the classification of fibromyalgia. Report of the Multicenter Criteria Committee. Arthritis Rheum. 1990;33(2):160-72.

3. Wolfe F, Ross K, Anderson J, Russell IJ, Hebert L. The prevalence and characteristics of fibromyalgia in the general population. Arthritis Rheum. 1995;38(1):19-28.

4. Mease P, Arnold LM, Choy EH, Clauw DJ, Crofford LJ, Glass JM, Martin SA, Morea J, Simon L, Strand CV et al. Fibromyalgia syndrome module at OMERACT 9: domain construct. J Rheumatol. 2009;36(10):2318-29.

5. Rohrbeck J, Jordan K, Croft P. The frequency and characteristics of chronic widespread pain in general practice: a case-control study. Br J Gen Pract. 2007;57(535):109-15

6. Mannerkorpi K, Burckhardt CS, Bjelle A. Physical performance characteristics of women with fibromyalgia. Arthritis Care Res. 1994;7(3):123-9.

7. Henriksen M, Lund H, Christensen R, Jespersen A, Dreyer L, Bennett RM, Danneskiold-Samsoe B, Bliddal H. Relationships between the fibromyalgia impact questionnaire, tender point count, and muscle strength in female patients with fibromyalgia: a cohort study. Arthritis Rheum. 2009;61(6):732-9.

8. Góes SM, Leite N, Shay BL, Homann D, Stefanello JMF, Rodacki ALF. Functional capacity, muscle strength and falls in women with fibromyalgia. Clin Biomech. 2012;27(6):578-83.

9. McLoughlin MJ, Colbert LH, Stegner AJ, Cook DB. Are women with fibromyalgia less physically active than healthy women? Med Sci Sports Exerc. 2011;43(5):905-12.

10. Alok R, Das SK, Agarwal GG, Tiwari SC, Salwahan L, Srivastava R. Problemfocused coping and self-efficacy as correlates of quality of life and severity of fibromyalgia in primary fibromyalgia patients. J Clin Rheumatol. 2014;20(6):314-6.

11. Wuytack F, Miller P. The lived experience of fibromyalgia in female patients, a phenomenological study. Chiropr Man Therap. 2011;19(1):22.

12. Liedberg GM, Henriksson CM. Factors of importance for work disability in women with fibromyalgia: an interview study. Arthritis Rheum. 2002;47(3):266-74.

13. Sallinen M, Kukkurainen ML, Peltokallio L, Mikkelsson M. "I'm tired of being tired" - Fatigue as experienced by women with fibromyalgia. Adv Physiother. 2011;13:11-7.

14. Wolfe F, Hawley DJ, Wilson K. The prevalence and meaning of fatigue in rheumatic disease. J Rheumatol. 1996;23(8):1407-17.

15. Ericsson A, Bremell T, Mannerkorpi K. Usefulness of multiple dimensions of fatigue in fibromyalgia. J Rehabil Med. 2013;45(7):685-93.

16. Vincent A, Benzo RP, Whipple MO, McAllister SJ, Erwin PJ, Saligan LN. Beyond pain in fibromyalgia: insights into the symptom of fatigue. Arthritis Res Ther. 2013;15(6):221.

17. Kurtze N, Svebak S. Fatigue and patterns of pain in fibromyalgia: correlations with anxiety, depression and co-morbidity in a female county sample. $\mathrm{Br}$ J Med Psychol. 2001;74(Pt 4):523-37. 
18. Nicassio PM, Moxham EG, Schuman CE, Gevirtz RN. The contribution of pain, reported sleep quality, and depressive symptoms to fatigue in fibromyalgia. Pain. 2002;100(3):271-9.

19. Rutledge $\mathrm{DN}$, Jones K, Jones CJ. Predicting high physical function in people with fibromyalgia. J Nurs Scholarsh. 2007;39(4):319-24.

20. Kop WJ, Lyden A, Berlin AA, Ambrose K, Olsen C, Gracely RH, Williams DA, Clauw DJ. Ambulatory monitoring of physical activity and symptoms in fibromyalgia and chronic fatigue syndrome. Arthritis Rheum. 2005;52(1):296-303.

21. Edwards RR, Bingham 3rd CO, Bathon J, Haythornthwaite JA. Catastrophizing and pain in arthritis, fibromyalgia, and other rheumatic diseases. Arthritis Rheum. 2006;55(2):325-32.

22. Lukkahatai N, Saligan LN. Association of catastrophizing and fatigue: a systematic review. J Psychosom Res. 2013;74(2):100-9.

23. Sarzi-Puttini P, Atzeni F, Salaffi F, Cazzola M, Benucci M, Mease PJ. Multidisciplinary approach to fibromyalgia: what is the teaching? Best Pract Res Clin Rheumatol. 2011:25(2):311-9.

24. Carville SF, Arendt-Nielsen S, Bliddal H, Blotman F, Branco JC, Buskila D, Da Silva JA, Danneskiold-Samsoe B, Dincer F, Henriksson C et al. EULAR evidence-based recommendations for the management of fibromyalgia syndrome. Ann Rheum Dis. 2008:67(4):536-41.

25. Puetz TW, Beasman KM, O'Connor PJ. The effect of cardiac rehabilitation exercise programs on feelings of energy and fatique: a meta-analysis of research from 1945 to 2005. Eur J Cardiovasc Prev Rehabil. 2006;13(6):886-93.

26. Busch AJ, Barber KA, Overend TJ, Peloso PM, Schachter CL. Exercise for treating fibromyalgia syndrome. Cochrane Database Syst Rev. 2007:4:CD003786.

27. Jones KD, Burckhardt CS, Deodhar AA, Perrin NA, Hanson GC, Bennett RM. A six-month randomized controlled trial of exercise and pyridostigmine in the treatment of fibromyalgia. Arthritis Rheum. 2008;58(2):612-22.

28. Pedersen BK, Saltin B. Evidence for prescribing exercise as therapy in chronic disease. Scand J Med Sci Sports. 2006;16 Suppl 1:3-63.

29. Busch AJ, Webber SC, Richards RS, Bidonde J, Schachter CL, Schafer LA, Danyliw A, Sawant A, Dal Bello-Haas V, Rader T et al. Resistance exercise training for fibromyalgia. Cochrane Database Syst Rev. 2013;12:CD010884.

30. Mannerkorpi K, Nordeman L, Cider A, Jonsson G. Does moderate-to-high intensity Nordic walking improve functional capacity and pain in fibromyalgia? A prospective randomized controlled trial. Arthritis Res Ther. 2010;12(5):R189.

31. Mannerkorpi K, Nordeman L, Ericsson A, Arndorw M. Pool exercise for patients with fibromyalgia or chronic widespread pain: a randomized controlled trial and subgroup analyses. J Rehabil Med. 2009;41(9):751-60

32. Larsson A, Palstam A, Lofgren M, Ernberg M, Bjersing J, Bileviciute-Ljungar I, Gerdle B, Kosek E, Mannerkorpi K. Resistance exercise improves muscle strength, health status and pain intensity in fibromyalgia-a randomized controlled trial. Arthritis Res Ther. 2015:17:161.

33. Ekman I, Swedberg K, Taft C, Lindseth A, Norberg A, Brink E, Carlsson J, Dahlin-Ivanoff S, Johansson IL, Kjellgren K et al. Person-centered care-ready for prime time. Eur J Cardiovasc Nurs. 2011;10(4):248-51.

34. Meeus M, Nijs J, Vanderheiden T, Baert I, Descheemaeker F, Struyf F. The effect of relaxation therapy on autonomic functioning, symptoms and daily functioning, in patients with chronic fatigue syndrome or fibromyalgia: a systematic review. Clin Rehabil. 2015;29(3):221-33.

35. Smets EM, Garssen B, Bonke B, De Haes JC. The Multidimensional Fatigue Inventory (MFI) psychometric qualities of an instrument to assess fatigue. J Psychosom Res. 1995;39(3):315-25.

36. Furst CJ, Ahsberg E. Dimensions of fatigue during radiotherapy. An application of the Multidimensional Fatigue Inventory. Support Care Cancer. 2001;9(5):355-60

37. Ericsson A, Mannerkorpi K. Assessment of fatigue in patients with fibromyalgia and chronic widespread pain. Reliability and validity of the Swedish version of the MFI-20. Disabil Rehabil. 2007;29(22):1665-70.

38. Burckhardt CS, Clark SR, Bennett RM. The fibromyalgia impact questionnaire: development and validation. J Rheumatol. 1991;18(5):728-33.

39. Hedin PJ, Hamne M, Burckhardt CS, Engstrom-Laurent A. The Fibromyalgia Impact Questionnaire, a Swedish translation of a new tool for evaluation of the fibromyalgia patient. Scand J Rheumatol. 1995;24(2):69-75.

40. Buysse DJ, Reynolds 3rd CF, Monk TH, Berman SR, Kupfer DJ. The Pittsburgh Sleep Quality Index: a new instrument for psychiatric practice and research. Psychiatry Res. 1989;28(2):193-213.
41. Theadom A, Cropley M, Humphrey KL. Exploring the role of sleep and coping in quality of life in fibromyalgia. J Psychosom Res. 2007;62(2):145-51.

42. Akkaya N, Akkaya S, Atalay NS, Acar M, Catalbas N, Sahin F. Assessment of the relationship between postural stability and sleep quality in patients with fibromyalgia. Clin Rheumatol. 2013;32(3):325-31.

43. Sullivan MJ, Bishop S, Pivik J. The Pain Catastrophizing Scale: development and validation. Psychol Assess. 1995;7(4):524-32.

44. Scott W, Wideman TH, Sullivan MJ. Clinically meaningful scores on pain catastrophizing before and after multidisciplinary rehabilitation: a prospective study of individuals with subacute pain after whiplash injury. Clin J Pain. 2014;30(3):183-90.

45. Osman A, Barrios FX, Kopper BA, Hauptmann W, Jones J, O'Neill E. Factor structure, reliability, and validity of the Pain Catastrophizing Scale. J Behav Med. 1997;20(6):589-605.

46. Osman A, Barrios FX, Gutierrez PM, Kopper BA, Merrifield T, Grittmann L. The Pain Catastrophizing Scale: further psychometric evaluation with adult samples. J Behav Med. 2000:23(4):351-65.

47. Campbell CM, McCauley L, Bounds SC, Mathur VA, Conn L, Simango M, Edwards RR, Fontaine KR. Changes in pain catastrophizing predict later changes in fibromyalgia clinical and experimental pain report: cross-lagged panel analyses of dispositional and situational catastrophizing. Arthritis Res Ther. 2012;14(5):R231.

48. Plazier M, Ost J, Stassijns G, De Ridder D, Vanneste S. Pain characteristics in fibromyalgia: understanding the multiple dimensions of pain. Clin Rheumatol. 2015;34(4):775-83.

49. Luciano JV, Guallar JA, Aguado J, Lopez-Del-Hoyo Y, Olivan B, Magallon R, Alda M, Serrano-Blanco A, Gili M, Garcia-Campayo J. Effectiveness of group acceptance and commitment therapy for fibromyalgia: a 6-month randomized controlled trial (EFFIGACT study). Pain. 2014;155(4):693-702.

50. Zigmond AS, Snaith RP. The hospital anxiety and depression scale. Acta Psychiatr Scand. 1983;67(6):361-70.

51. Herrmann C. International experiences with the Hospital Anxiety and Depression Scale-a review of validation data and clinical results. Psychosom Res. 1997:42(1):17-41.

52. Mannerkorpi K, Hernelid C. Leisure Time Physical Activity Instrument and Physical Activity at Home and Work Instrument. Development, face validity, construct validity and test-retest reliability for subjects with fibromyalgia. Disabil Rehabil. 2005:27(12):695-701.

53. Mannerkorpi K, Svantesson U, Carlsson J, Ekdahl C. Tests of functional limitations in fibromyalgia syndrome: a reliability study. Arthritis Care Res. 1999;12(3):193-9.

54. Fayers P, Machin D. Quality of life: the assessment, analysis and interpretation of patient-reported outcomes. Chichester: Wiley; 2007.

55. Papadopoulou D, Fassoulaki A, Tsoulas C, Siafaka I, Vadalouca A. A meta-analysis to determine the effect of pharmacological and nonpharmacological treatments on fibromyalgia symptoms comprising OMERACT-10 response criteria. Clin Rheumatol. 2016:35(3):573-86.

56. Humphrey L, Arbuckle R, Mease P, Williams DA, Samsoe BD, Gilbert C. Fatigue in fibromyalgia: a conceptual model informed by patient interviews. BMC Musculoskelet Disord. 2010;11:216

57. Vincent A, Hoskin TL, Whipple MO, Clauw DJ, Barton DL, Benzo RP, Williams DA. OMERACT-based fibromyalgia symptom subgroups: an exploratory cluster analysis. Arthritis Res Ther. 2014:16(5):463.

58. Bjersing JL, Erlandsson M, Bokarewa MI, Mannerkorpi K. Exercise and obesity in fibromyalgia: beneficial roles of IGF-1 and resistin? Arthritis Res Ther. 2013;15(1):R34

59. Palstam A, Larsson A, Lofgren M, Ernberg M, Bjersing J, Bileviciute-Ljungar I, Gerdle B, Kosek E, Mannerkorpi K. Decrease of fear avoidance beliefs following person-centered progressive resistance exercise contributes to reduced pain disability in women with fibromyalgia: secondary exploratory analyses from a randomized controlled trial. Arthritis Res Ther. 2016;18(1):116.

60. Guymer EK, Clauw DJ. Treatment of fatigue in fibromyalgia. Rheum Dis Clin North Am. 2002;28(2):367-78

61. Choy EH, Arnold LM, Clauw DJ, Crofford LJ, Glass JM, Simon LS, Martin SA, Strand CV, Williams DA, Mease PJ. Content and criterion validity of the preliminary core dataset for clinical trials in fibromyalgia syndrome. Rheumatol. 2009:36(10):2330-4

62. Jones KD, Burckhardt CS, Clark SR, Bennett RM, Potempa KM. A randomized controlled trial of muscle strengthening versus flexibility training in fibromyalgia. J Rheumatol. 2002;29(5):1041-8. 
63. Hakkinen A, Hakkinen K, Hannonen P, Alen M. Strength training induced adaptations in neuromuscular function of premenopausal women with fibromyalgia: comparison with healthy women. Ann Rheum Dis. 2001;60(1):21-6.

64. Busch AJ, Schachter CL, Overend TJ, Peloso PM, Barber KA. Exercise for fibromyalgia: a systematic review. J Rheumatol. 2008;35(6):1130-44.

65. Jones KD. Recommendations for resistance training in patients with fibromyalgia. Arthritis Res Ther. 2015;17:258.

66. Nelson NL. Muscle strengthening activities and fibromyalgia: a review of pain and strength outcomes. J Bodyw Mov Ther. 2015;19(2):370-6.

67. Lindheimer JB, O'Connor PJ, Dishman RK. Quantifying the placebo effect in psychological outcomes of exercise training: a meta-analysis of randomized trials. Sports Med. 2015:45(5):693-711.

Submit your next manuscript to BioMed Central and we will help you at every step:

- We accept pre-submission inquiries

- Our selector tool helps you to find the most relevant journal

- We provide round the clock customer support

- Convenient online submission

- Thorough peer review

- Inclusion in PubMed and all major indexing services

- Maximum visibility for your research

Submit your manuscript at www.biomedcentral.com/submit
) Biomed Central 